\title{
Magnetic Circuit Design and Finite Element Simulation Analysis of Magnetic Fluid Rotating Dynamic Sealing Device
}

\author{
Xiaojuan Li*, Jin Zhang, Ling Yi, Yunliang Zhu, Shuo Jia, Bing Ma, Yabing Li \\ Beijing Smart Core Microelectronics Technology Co., Ltd, Changping, Beijing, 102200, China \\ *Corresponding Author.
}

\begin{abstract}
The magnetic fluid rotary dynamic sealing device is based on the magnetic fluid material. The typical sealing structure is to fill the magnetic fluid in the gap between the shaft and the magnetic pole, and keep it in the sealing gap under the action of the external magnetic field to form a liquid "O"-shaped sealing ring to block $i$. The sealing effect of this kind of device largely depends on the design of the magnetic circuit structure of the device. In this paper, ANSYS finite element simulation is used to analyze the influence of seal stages, tooth shape and the number of permanent magnets on the magnetic fluid rotating dynamic seal. The L9 $\left(3^{4}\right)$ factor level table is designed by orthogonal test method to analyze the priority of the influence of tooth width, seal clearance and chamfering on the magnetic fluid sealing performance, which provides the reference for the structural design and magnetic circuit design of magnetic fluid rotating dynamic seal.
\end{abstract}

Keywords: ANSYS, magnetic fluid, seal

\section{Introduction}

Magnetic fluid, also known as magnetic fluid, ferromagnetic fluid or magnetic fluid, which is a new type of functional material, it has both the fluidity of liquid and the magnetism of solid magnetic materials. It is a kind of stable colloidal liquid which is composed of magnetic solid particles, base carrier (also called media) and interfacial active agent with the diameter of nanometer (less than $10 \mathrm{~nm}$ ). The fluid has no magnetic attraction in static state, and only shows magnetism when applied with magnetic field. The magnetic fluid produced by nanometer metal and alloy powder has excellent performance, which can be widely used in various fields such as magnetic fluid sealing, shock absorption, medical equipment, sound regulation, light display, magnetic fluid beneficiation and so on under various harsh conditions [1-3].

Nano magnetic fluid seal is realized by the response of nano magnetic fluid to magnetic field [4-5]. The sealing principle of nano magnetic fluid rotating shaft is shown in Fig. 1, mainly excluding permanent magnet, annular pole and rotating shaft. There are a number of cogged focusing structures on the inner surface of the static pole, which generate a strong magnetic field in the gap between the pole and the rotating shaft, inject the nano magnetic fluid into the gap with a strong magnetic field, and the nano magnetic fluid is constrained in the gap. In this way, under the action of magnetic field, the nano magnetic fluid generates volume force, which is balanced in the gap of focusing structure. The liquid "O" ring is formed, and the shaft can rotate freely in the liquid "O" ring. When the nano magnetic fluid is affected by the pressure difference, it will move slightly in the non-uniform magnetic field. Due to the existence of the magnetic field gradient, the magnetic force against the pressure difference is generated, so as to achieve a new balance and play a sealing role. This is the principle of the nano magnetic fluid sealer. Fig. 1 is the schematic diagram of nanomagnetic fluid seal. The sealing ability of the magnetic fluid seal depends on the magnetic field of the sealing gap and the magnetization strength of the magnetic fluid, so the magnetic circuit design of the sealing device is very important [6-7].

ISSN: 0010-8189

(C) CONVERTER 2021 

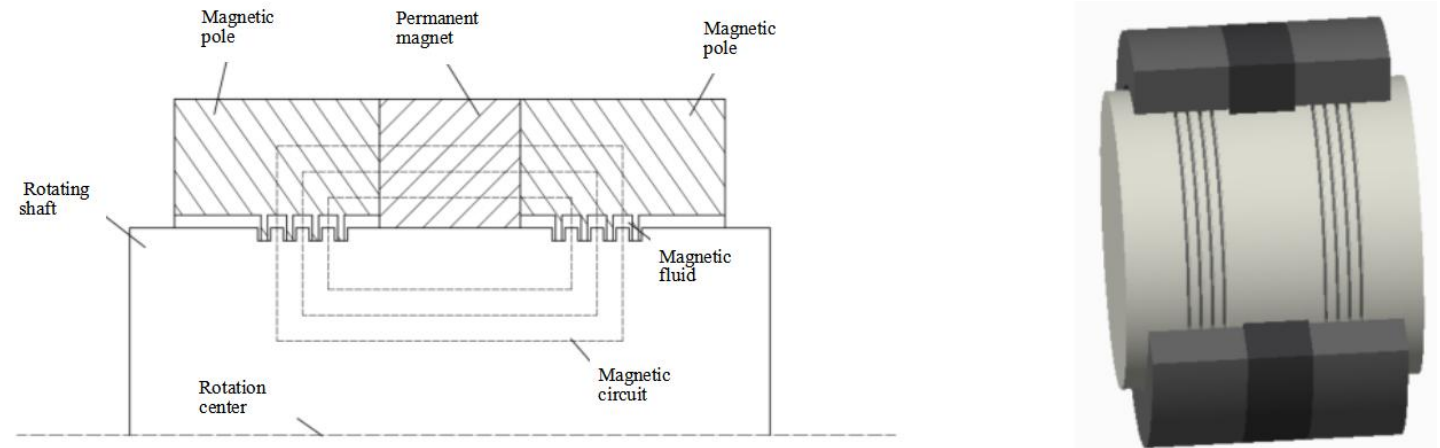

(a) Schematic diagram of nano magnetic fluid seal $\quad$ (b) 3D model diagram of nano magnetic fluid seal Fig. 1 Schematic diagram of nanomagnetic fluid seal

Magnetic fluid seal can achieve zero leakage: no friction; no pre tightening force is needed to avoid the deformation caused by pre tightening force in the assembly process; instantaneous overpressure can be reset automatically when the pressure drops; both sides of the seal can be sealed without directional restrictions and other advantages.

Without considering the influence of rotating speed, the calculation formula of sealing pressure is:

$$
\Delta \mathrm{P}_{\max }=\frac{\mathrm{M}_{\mathrm{s}} \mathrm{H}_{\max }}{4 \pi}\left[1-\frac{\mathrm{H}_{\min }}{\mathrm{H}_{\max }}\right] \times 10^{-7}
$$

MS - saturation magnetization of magnetic fluid, G.

$\mathrm{H}$ - magnetic field strength at the sealing gap, G

\section{Structure Design of Magnetic Fluid Seal}

The inner surface of two symmetrical pole shoes is processed with multi-stage pole teeth to form multi-stage seal. There is a gap between pole teeth and shaft, which is filled with magnetic liquid. When the space on both sides is affected by the pressure difference, the deformed magnetic liquid will be affected by the magnetic force to resist the pressure difference [8-10].

Indicator: $\Delta \mathrm{p}$

Affecting sealing capacity factors: tooth width $\mathrm{b}(\mathrm{mm})$, tooth height $\mathrm{lh}(\mathrm{mm})$, groove width $1 \mathrm{~s}(\mathrm{~mm})$, chamfer $\alpha\left({ }^{\circ}\right)$, sealing clearance $\lg (\mathrm{mm})$, tooth end width $\mathrm{lt}(\mathrm{mm})$, magnetic pole material, permanent magnet material and volume. Fig. 2 is the model and tooth profile parameters. 


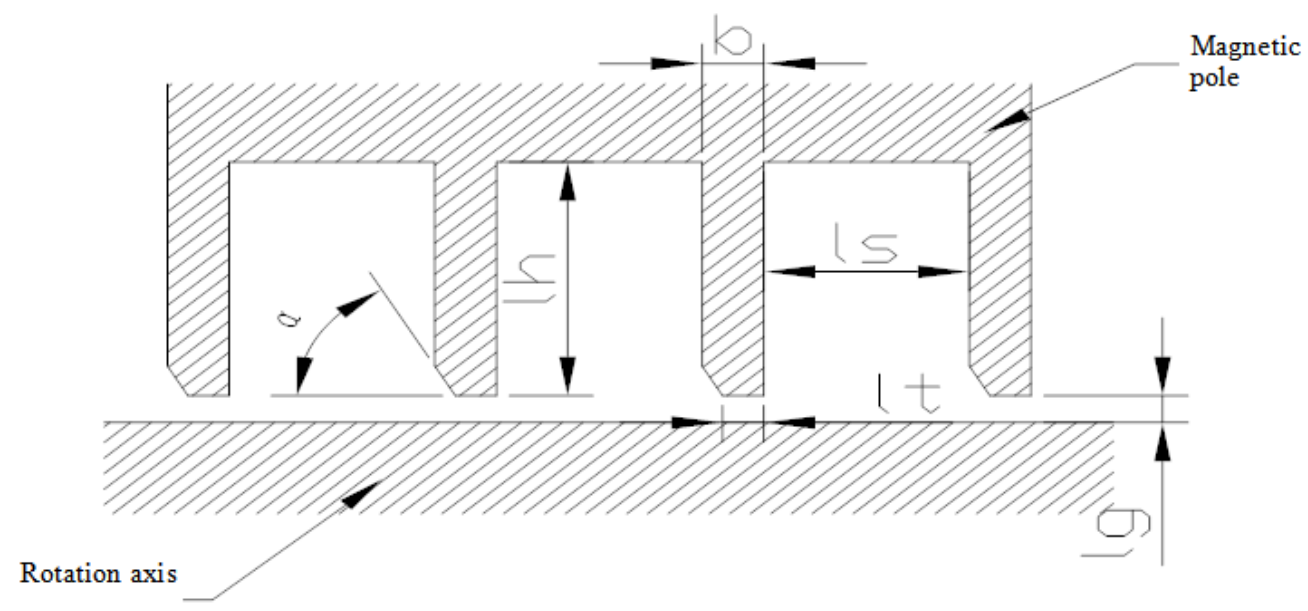

Fig. 2 Model and tooth profile parameters

\section{Simulation and Analysis of Magnetic Fluid Seal with ANSYS Software}

The material parameters in the finite element simulation set in this paper are as follows:

Cylinder block: $\mu \mathrm{r}=1$

Bearing: $\mu \mathrm{r}=1$

Pole material: 45 steel, $\mu \mathrm{r}=1450$

Magnetic guide shaft: 45 steel, $\mu \mathrm{r}=1450$

Permanent magnet: $\mathrm{NdFeB}$, relative permeability: $\mu \mathrm{r}=1.05$, coercive force: $\mathrm{HC}=8.76 \times 105 \mathrm{a} / \mathrm{m}$,

$30 \mathrm{~mm}$ thickness for air field is selected

Saturation magnetization of magnetic fluid Ms $=5000 \mathrm{~g}$

Unit selection: plane53

Cell grid generation accuracy: intelligent level 1.

The simulation results of magnetic fluid sealing are shown in Fig. 3.

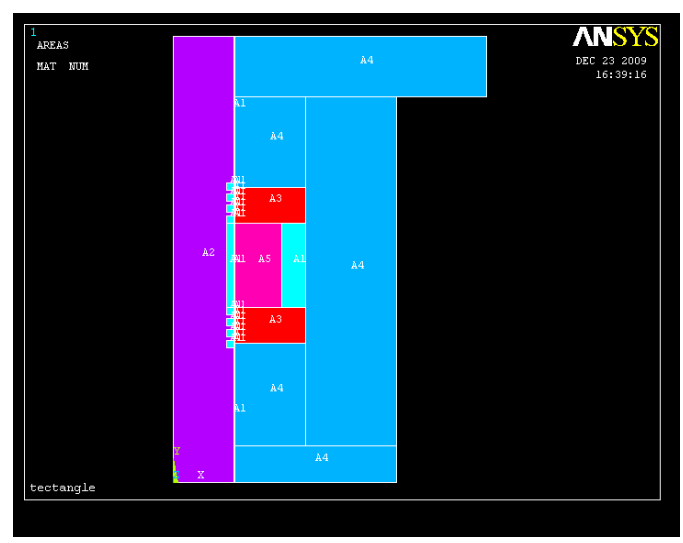

(a) Section of magnetic fluid seal model

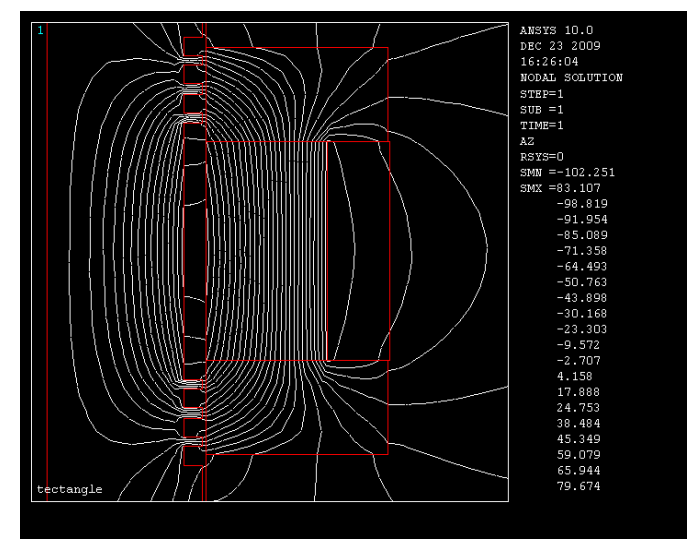

(b) Distribution of magnetic field lines of magnetic fluid seal is simulated by ANSYS

Fig. 3 Simulation diagram of magnetic fluid seal

3.1 Orthogonal test analysis

ISSN: 0010-8189

(C) CONVERTER 2021 
Tooth width $\mathrm{b}=1 \mathrm{~mm}$, tooth height $\mathrm{lh}=2 \mathrm{~mm}$, groove width $1 \mathrm{~s}=3.5 \mathrm{~mm}$ are fixed, sealing clearance $1 \mathrm{~g}=0.1 \mathrm{~mm}$, the influence of chamfering and tooth end width are considered, table 3 factor level table is developed and L9 $\left(3^{4}\right)$ orthogonal experiment is carried out. The factor level table and simulation results of the orthogonal experiment are shown in Table1 and Table 2.

Table 1 Factor level table

\begin{tabular}{|c|c|c|c|}
\hline Factor & $\begin{array}{c}\text { Chamfer } \\
\alpha\left(^{\circ}\right)\end{array}$ & $\begin{array}{c}\text { Tooth end width } \\
\text { lt (mm) }\end{array}$ & Seal clearance (mm) \\
\hline 1 & 30 & 0.25 & 0.05 \\
\hline 2 & 45 & 0.5 & 0.08 \\
\hline 3 & 60 & 0.75 & 0.1 \\
\hline
\end{tabular}

Table 2 Orthogonal experiment table

\begin{tabular}{|c|c|c|c|c|}
\hline Lab number & $\begin{array}{c}\text { Chamfer } \\
\alpha\left(^{\circ}\right)\end{array}$ & $\begin{array}{l}\text { Tooth end width } \\
\text { lt }(\mathrm{mm})\end{array}$ & $\begin{array}{c}\text { Seal } \\
\text { clearance } \\
(\mathrm{mm})\end{array}$ & $\begin{array}{l}\text { Average single } \\
\text { stage seal } \\
\text { differential } \\
\text { pressure }(\mathrm{KPa})\end{array}$ \\
\hline 1 & 30 & 0.5 & 0.1 & 872.681 \\
\hline 2 & 45 & 0.75 & 0.05 & 1668.418 \\
\hline 3 & 60 & 0.25 & 0.08 & 1430.626 \\
\hline 4 & 30 & 0.75 & 0.08 & 946.367 \\
\hline 5 & 45 & 0.25 & 0.1 & 1087.717 \\
\hline 6 & 60 & 0.5 & 0.05 & 1977.25 \\
\hline 7 & 30 & 0.25 & 0.05 & 2006.68 \\
\hline 8 & 45 & 0.5 & 0.08 & 1148.167 \\
\hline 9 & 60 & 0.75 & 0.1 & 781.111 \\
\hline K1 & 3825.728 & 4525.023 & 5652.348 & \multirow{4}{*}{11919.017} \\
\hline $\mathrm{K} 2$ & 3904.302 & 3998.098 & 3525.16 & \\
\hline K3 & 4188.987 & 3395.896 & 2741.509 & \\
\hline $\mathrm{R}$ & 363.259 & 1129.127 & 2910.839 & \\
\hline
\end{tabular}

\subsection{Influence of tooth shape}

Tooth width, tooth height, groove width, chamfer, sealing clearance and sealing stage are fixed, Tooth width $b=$ $1 \mathrm{~mm}$, tooth height $\mathrm{lh}=2 \mathrm{~mm}$, groove width $1 \mathrm{~s}=3.5 \mathrm{~mm}$, chamfer $\alpha=60^{\circ}$, sealing clearance $1 \mathrm{~g}=0.1 \mathrm{~mm}$, sealing stage is 6, Rectangle, one side bevel trapezoid, two sides bevel trapezoid and right triangle are designed, the results of ANSYS simulation analysis are shown in Table3:

Table 3 Simulation results of seal with different tooth shapes

\begin{tabular}{|c|c|c|c|c|}
\hline lt $(\mathrm{mm})$ & Tooth profile & $\begin{array}{c}\text { Seal pressure } \\
\text { difference }(\mathrm{KPa})\end{array}$ & $\begin{array}{c}\text { Average single stage seal } \\
\text { differential pressure }(\mathrm{KPa})\end{array}$ & Shape \\
\hline 1 & Rectangle & 3981.116 & 663.519 & $/$ \\
\hline 0.75 & Trapezoid & 4686.664 & 781.111 & $\begin{array}{c}\text { Unilateral oblique } \\
\text { angle }\end{array}$ \\
\hline 0.5 & Trapezoid & 5664.689 & 944.115 & Unilateral oblique \\
\hline
\end{tabular}


CONVERTER MAGAZINE

Volume 2021, No. 5

\begin{tabular}{|c|c|c|c|c|}
\hline & & & & angle \\
\hline 0.25 & Trapezoid & 7128.134 & 1188.022 & $\begin{array}{c}\text { Unilateral oblique } \\
\text { angle }\end{array}$ \\
\hline 0.1875 & Trapezoid & 7181.856 & 1196.976 & $\begin{array}{c}\text { Unilateral oblique } \\
\text { angle }\end{array}$ \\
\hline 0.15 & Trapezoid & 7615.141 & 1269.190 & $\begin{array}{c}\text { Unilateral oblique } \\
\text { angle }\end{array}$ \\
\hline 0.125 & Trapezoid & 7793.233 & 1298.872 & $\begin{array}{c}\text { Unilateral oblique } \\
\text { angle }\end{array}$ \\
\hline 0.1 & Trapezoid & 8890.211 & 1481.702 & $\begin{array}{c}\text { Unilateral oblique } \\
\text { angle }\end{array}$ \\
\hline- & Triangle & 6753.856 & 844.232 & $\begin{array}{c}\text { Unilateral oblique } \\
\text { angle }\end{array}$ \\
\hline 0.42 & Trapezoid & 6032.038 & 1005.340 & $\begin{array}{c}\text { Bilateral oblique } \\
\text { angle }\end{array}$ \\
\hline
\end{tabular}

The finite element analysis of ANSYS shows that under other same conditions, with the gradual reduction of the width of the tooth end, in the process of transition from rectangle, trapezoid to triangle, the seal pressure difference increases first and then decreases.

The tooth structure generally of rectangular magnetic and trapezoidal teeth are adopted, rectangular magnetic has large pressure resistance capacity, the same pressure resistance on both sides, simple processing technology and easy to guarantee performance; the magnetic field gradient of trapezoidal teeth is large, and the interface stability of magnetic liquid is good.

In multipole seal, the sealing ability of bilateral bevel tooth (trapezoid tooth) is better than that of rectangular tooth, which has better magnetic gathering effect and can bear more sealing pressure. Under the same conditions, the sealing effect of double bevel trapezoid is better than that of single bevel trapezoid.

(3) The influence of the number of permanent magnets

Under the same tooth profile, two permanent magnets and a single permanent magnet are used for simulation analysis, and the simulation data is shown in Table 4:

Table 4 Simulation results of sealing capacity of different numbers of permanent magnets

\begin{tabular}{|c|c|c|c|c|c|c|}
\hline \multirow[b]{2}{*}{$\begin{array}{c}\text { Seal } \\
\text { progres } \\
\text { sion }\end{array}$} & \multicolumn{3}{|c|}{ Single permanent magnet } & \multicolumn{3}{|c|}{ Two permanent magnets } \\
\hline & $\begin{array}{c}\operatorname{Hmax} \\
(106 \mathrm{~A} / \mathrm{m})\end{array}$ & $\begin{array}{c}\text { Hmin } \\
(106 \mathrm{~A} / \mathrm{m})\end{array}$ & $\begin{array}{l}\text { Single pole } \\
\text { average seal } \\
\text { pressure } \\
\text { difference } \\
(\mathrm{KPa})\end{array}$ & $\begin{array}{c}\operatorname{Hmax} \\
(106 \mathrm{~A} / \mathrm{m})\end{array}$ & $\begin{array}{c}\text { Hmin } \\
(106 \mathrm{~A} / \mathrm{m})\end{array}$ & $\begin{array}{l}\text { Single pole } \\
\text { average seal } \\
\text { pressure } \\
\text { difference } \\
(\mathrm{KPa})\end{array}$ \\
\hline 1 & 1.6992 & 0.078882 & \multirow{6}{*}{663.519} & 1.5965 & 0.098386 & \multirow{6}{*}{1075.566} \\
\hline 2 & 1.2684 & 0.082725 & & 1.6147 & 0.097306 & \\
\hline 3 & 1.2958 & 0.082725 & & 3.3146 & 0.20536 & \\
\hline 4 & 1.3009 & 0.077433 & & 3.3676 & 0.2066 & \\
\hline 5 & 1.2836 & 0.077433 & & 1.6107 & 0.097535 & \\
\hline 6 & 1.2124 & 0.076325 & & 1.5981 & 0.09737 & \\
\hline
\end{tabular}

\section{Analysis of Simulation Results}

(1) Under the same sealing clearance, groove width and tooth height, comparing the three tooth shapes of rectangle, triangle and trapezoid, the trapezoid has the largest sealing capacity and the rectangle has the smallest. It is inferred

ISSN: 0010-8189

(C) CONVERTER 2021 
that there is a tooth profile that has the greatest sealing ability during the gradual reduction of the tooth end width, and its pressure resistance is determined by the value of the tooth end width and the chamfer $\alpha$.

(2) Under the same conditions, the double-sided bevel has better sealing performance than the single-sided bevel.

(3) The results of orthogonal experiment show that the sealing capacity of the device is influenced by the sealing clearance, the width of tooth end and chamfering.

(4) Within a certain range, the smaller the sealing gap, the stronger the sealing ability. If the sealing gap is too small, it is easy to cause friction between the sealing shaft and the tooth top. Under the condition that the machining accuracy can be satisfied, the small sealing gap should be selected as much as possible.

(5) The use of multiple permanent magnets can significantly improve the sealing ability of the device. The maximum magnetic induction intensity at the central tooth profile of the two permanent magnets is twice the maximum magnetic induction intensity at the edge tooth profile. Therefore, considering the repulsive force between the magnets, it can be Use multiple permanent magnets.

\section{References}

[1] R.R. K, “Moskowitz Commercial,” Applications of Ferrofluids, vol. 1990, no.85.

[2] W. Ochonski, "Dynamic sealing with magnetic fluids," vol. 1989, no. 01.

[3] B. Zarina, W. Bill, "New low cost ferrofluidic sealing challenges the mechanical seal," vol. 1997, no. 06.

[4] I. Etsion, "Ideas and tendencies in future mechanical seal development," Lubrication Engineering, vol. 1990, no. 2, pp. 122-125.

[5] G. Itzhnk, "Real time monitoring and control mechanical of face-seal dynamic behavior," Sealing Technology, vol. 11, no. 96, pp. 6-11, 2001.

[6] O. Pinkus, "Model testing of magnetic fluid seals," ASLE Transactions, vol. 25, no.1, pp. 79-81, 1982.

[7] M.O. Lutest, "Experimental studies of high speed cryogenic magnetic fluid seals," IEEE Transactions on MAG, vol. 16, no. 2, pp. 243 246, 1980.

[8] Z.Y. Yu, W. Zhang, "Application of magnetic fluid seal in water turbine shaft," Journal of Drainage and Irrigation Machinery Engineering, vol. 32, no. 2, pp. 151-155, 2014.

[9] Y.ZHANG, J.B. ZHANG, X.J. SHAO, "Magnetic field calculation of rectangular poled magnetic fluid sealing device," Lubrication Engineering, vol. 2002, no. 4, pp. 4-26.

[10] F.Y. CHEN, Y.G. FAN, Y. WANG, "The influence of viscous loss in the magnetic fluid seal," Lubrication Engineering, vol. 35, no. 7, pp. 65-67, 2010. 